\title{
Assessing the authenticity of single seed vegetable oils using fatty acid stable carbon isotope ratios $\left({ }^{13} \mathrm{C} /{ }^{12} \mathrm{C}\right)$
}

\author{
S. Kelly, ${ }^{*}$ I. Parker, M. Sharman, J. Dennis \& I. Goodall \\ CSL Food Science Laboratory, Norwich Research Park, Colney, Norwich NR4 7UQ, UK
}

(Received 16 May 1996; revised version received 5 August 1996; accepted 5 August 1996)

\begin{abstract}
The authenticity of single seed vegetable oils which utilise the $C_{3}$ photosynthetic pathway was investigated using gas chromatography-combustion-stable isotope ratio mass spectrometry (GC-C-SIRMS). Samples of authentic groundnut, palm, rapeseed and sunflower oils were derivatised to form fatty acid methyl esters (FAMEs) and their carbon isotope ratios $\left({ }^{13} \mathrm{C} /{ }^{12} \mathrm{C}\right.$ ) determined. In-house reference materials (IHRMs) and internal standards were used routinely to monitor the extraction procedure and SIRMS measurement. These materials demonstrated the consistent performance of the technique. $\delta^{13} \mathrm{C} \%$ data for the authentic vegetable oil fatty acids fell into the narrow range of $-27.6 \%$ to $-32 \cdot 1 \%$. However, the values within the oil varieties considered were significantly different. The data from sunflower oils were such that they could be separated from the other varieties by canonical discriminant analysis. The determination of fatty acid carbon isotope ratios may therefore provide an additional indication of the varietal authenticity of oils which use the $C_{3}$ photosynthetic pathway. Crown Copyright (C) 1997 Published by Elsevier Science Ltd
\end{abstract}

\section{INTRODUCTION}

Single seed vegetable oils carry a premium price either due to cited health benefits or to the properties they possess for culinary use. Economic incentives therefore exist to mix, or completely replace, these products with inferior or cheaper oils. Detection of this type of adulteration is often difficult because of uncertaintics associated with existing methods of oil analysis, such as determination of fatty acid composition, sterol analysis and iodine number. For example, the detection of adulteration by determination of fatty acid composition is limited by overlap in a number of single seed oils (Rossell, 1991). Furthermore, blending of cheaper oils can give compositions similar to that of a premium oil.

The use of stable carbon isotope ratio analysis (SCIRA) to determine food authenticity is well documented in the literature (Brookes et al., 1991; Doner, 1985, 1991; Bricout \& Koziet, 1987; Koziet et al., 1993). The potential of the technique to detect the adulteration of corn oil with cheaper common alternatives has been demonstrated (Rossell, 1994).

*To whom correspondence should be addressed.
Detection is made possible because of significant differences between the ${ }^{13} \mathrm{C} /{ }^{12} \mathrm{C}$ isotope ratios of corn and other oil types. In all of the above cases, the global isotopic composition of the oil is measured by combusting the whole sample to generate $\mathrm{CO}_{2}$ and analysing the mass distribution of the gas with a stable isotope mass spectrometer. Data from these measurements are expressed relative to the international standard, Pee Dee Belemnite (PDB), using the following formula:

$$
\delta^{13} \mathrm{C} \%=\frac{\left[{ }^{13} \mathrm{C} /{ }^{12} \mathrm{C}\right]_{\text {sample }}-\left[{ }^{13} \mathrm{C} /{ }^{12} \mathrm{C}\right]_{\text {standard (PDB) }}}{\left[{ }^{13} \mathrm{C} /{ }^{12} \mathrm{C}\right]_{\text {standard (PDB) }}} \times 10^{3}
$$

The $\delta^{13} \mathrm{C} \%$ (delta carbon-13 per mille) value for vegetable oils depends upon the photosynthetic pathway used by the plant to fix atmospheric $\mathrm{CO}_{2}$. Most plants used in the production of vegetable oils, such as rape and groundnut, utilise the $\mathrm{C}_{3}$ or Calvin cycle, resulting in relatively depleted global $\delta^{13} \mathrm{C} \%$ values of between -25 and -30 (Rossell, 1991).

Corn is one of a small number of plants which use the $\mathrm{C}_{4}$ or Hatch-Slack photosynthetic cycle. This pathway is less discriminating against the ${ }^{13} \mathrm{C}$ isotope than the $\mathrm{C}_{3}$ route and hence produces an oil that is relatively 
enriched in carbon-13. Authentic corn oils typically have global $\delta^{13} \mathrm{C} \%$ values between -14.3 and -16.4 (personal communication, Leatherhead Food Research Association, 1994). Therefore, adulteration of corn oil with $\mathrm{C}_{3}$ vegetable oils can be detected relatively easily, as it results in global $\delta^{13} \mathrm{C} \%$ values between the upper limit for authentic $\mathrm{C}_{3}$ vegetable oils and the lower limit for authentic $\mathrm{C}_{4}$ corn oils.

However, global $\delta^{13} \mathrm{C} \%$ values from $\mathrm{C}_{3}$ vegetable oils show only a small natural variation. These differences are insufficient to distinguish between authentic $\mathrm{C}_{3}$ vegetable oils and mixtures of different $C_{3}$ oil types.

Extensive surveys by various organisations worldwide have established rigid guidelines for the natural variation of fatty acid compositions in commercial oils (FOSFA International, 1994). This has enabled improvements in the ease of detection of adulterated oils using comparatively inexpensive and established techniques, such as gas chromatography with flame ionisation detection. However, natural variation in fatty acid composition means it is possible to adulterate premium oils by adding low levels $(<10 \%)$ of cheaper varieties and avoid detection. The overlap of compositional ranges also makes it possible to completely substitute a premium oil by blending other varieties to give the same fatty acid profile.

As no single technique currently reported will unambiguously determine the authenticity of all vegetable oil types, an isotopic study of individual fatty acids was undertaken. The potential for detecting vegetable oil adulteration was assessed using gas chromatographycombustion-stable isotope ratio mass spectrometry (GC-C-SIRMS). This technique couples GC with SCIRA, permitting the carbon isotope ratios of specific food components to be measured directly after separation by capillary GC. In this paper we report the $\delta^{13} \mathrm{C} \%$ values of individual fatty acids in $\mathrm{C}_{3}$ vegetable oils after derivatisation to their corresponding methyl esters (FAMEs). A database detailing the isotope ratios of the major fatty acids (palmitic, stearic, oleic, linoleic) in cach oil type was compiled. Finally, the discriminatory power of the technique to establish $C_{3}$ vegetable oil authenticity was investigated.

\section{MATERIALS AND METHODS}

\section{Authentic single seed vegetable oil samples}

Samples of authentic single seed vegetable oils from various worldwide locations were obtained and supplied by CSL Food Science Laboratory, Torry. All of these oils were production samples with fully documented histories, originally sourced from reputable contacts in the oil manufacturing industry.

\section{Sample preparation}

The fatty acid methylation technique was developed by Christie (1989). The methylating reagent was a mixture of sulphuric acid (BDH, Aristar grade) and methanol (Rathburn Chemicals, HPLC grade) with toluene (Rathburn Chemicals, glass distilled grade) as solubiliser. This reagent stores well, was convenient to prepare and had a relatively low toxicity compared to alternative methylating reagents (Hamilton \& Rossell, 1986). The same batch of methanol was used to derivatise all the oil samples.

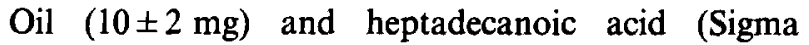
Chemical Company) $(4 \pm 1 \mathrm{mg}$ ) were accurately weighed into a $10 \mathrm{ml}$ Reacti-Vial. The oil and heptadecanoic acid were dissolved in toluene $(1 \mathrm{ml})$ and sulphuric acid in methanol $(1 \% \mathrm{v} / \mathrm{v}, 2 \mathrm{ml})$. A few crystals of butylated hydroxytoluene (Sigma) were added to the oil sample to inhibit oxidation of the sample by air. The Reacti-Vial was sealed with a screw cap and its contents were mixed by vortexing. The sample was placed on a platform shaker in a thermostatted oven and agitated at $50 \pm 5^{\circ} \mathrm{C}$ overnight.

The Reacti-Vial was removed from the oven and allowed to cool to room temperature. Aqueous sodium chloride solution $(5 \% \mathrm{w} / \mathrm{v}, 3 \mathrm{ml})$ was added and the methyl esters were extracted by vortexing with hexane (Rathburn Chemicals, HPLC grade) $(2 \times 2 \mathrm{ml})$. The upper organic layer was quantitatively transferred and combined in a screw-capped test tube using a glass Pasteur pipette. The hexane extract was washed with aqueous potassium bicarbonate solution $(2 \% \mathrm{w} / \mathrm{v}$, $2 \mathrm{ml}$ ). The organic layer was quantitatively transferred to a volumetric flask $(5 \mathrm{ml})$ using a glass Pasteur pipette. A solution of methyl heneicosanoate (Sigma) in hexane $\left(40 \mathrm{mg} \mathrm{ml}^{-1}, 100 \mu \mathrm{l}\right)$ was added to the volumetric flask and the contents diluted to volume with hexane.

\section{Gas chromatography-combustion-stable isotope ratio mass spectrometry (GC-C-SIRMS)}

\section{Gas chromatography}

The separation of the individual FAMEs was achieved using a Hewlett-Packard 5890 Series II gas chromatograph fitted with a capillary column $(0.32 \mathrm{~mm}$ i.d. $x$ $25 \mathrm{~m}$ length) of fused silica coated with FFAP-CB (film thickness $0.3 \mu \mathrm{m}$ ) (Chrompack). Helium was used as a carrier gas and injection was in split mode with a split ratio of 20:1 via an A200S autosampler. The following temperature programme was used: initial oven temperature, $160^{\circ} \mathrm{C}$; programme rate, $2^{\circ} \mathrm{C} \mathrm{min}^{-1}$; final oven temperature, $240^{\circ} \mathrm{C}$.

\section{Stable isotope ratio mass spectrometry (SIRMS)}

The column effluent was passed into a combustion interface at $940^{\circ} \mathrm{C}$ which quantitatively oxidised each of the FAMEs into $\mathrm{CO}_{2}$ and water. The resulting $\mathrm{CO}_{2}$ was swept into the SIRMS system (Delta S, Finnigan MAT, Bremen, Germany) by a stream of helium carrier gas. The mass spectrometer measured the relative abundance of the $44\left({ }^{12} \mathrm{CO}_{2}\right)$ and 45 ions $\left({ }^{13} \mathrm{CO}_{2}\right)$. Pulses of calibrated $\mathrm{CO}_{2}$ reference gas of known isotope ratio were superimposed on the column effluent at predetermined 
times. This permitted measurement of the carbon isotopic ratio $\left(\delta^{13} \mathrm{C} \%\right)$ of the sample by comparison with the isotope ratio of the $\mathrm{CO}_{2}$ reference gas. The reference gas was calibrated relative to the PDB scale using carbonate standard reference material NBS-19.

\section{Quality control}

In-house reference materials (IHRMs)

Both sunflower $\left(\mathrm{C}_{3}\right)$ and corn oil $\left(\mathrm{C}_{4}\right)$ IHRMs were employed to monitor the derivatisation and extraction procedure and provide between-batch repeatability of the isotope ratio data. Five replicate preparations of each IHRM were made for GC-C-SIRMS analysis to establish nominal $\delta^{13} \mathrm{C} \%$ values and standard deviation for the fatty acids present in the reference materials. One of the IHRMs was then routinely incorporated into the batch processing of the authentic oils. Batches were considered to be 'in-control' if the reference sample data were within \pm 3 standard deviations (SD) of their established values.

Heptadecanoic acid internal standard $\left(C_{17} I S\right)$ and methyl heneicosanoate $G C$ standard $\left(C_{2 I} G C\right.$ standard)

Heptadecanoic acid $\left(C_{17: 0}\right)$ internal standard was weighed into each of the samples before derivatisation and extraction. This allowed the effect of derivatisation and extraction on the repeatability of the ${ }^{13} \mathrm{C} /{ }^{12} \mathrm{C}$ measurement to be monitored in individual samples. The addition of methyl heneicosanoate $\left(\mathrm{C}_{21: 0}\right)$ after derivatisation and extraction facilitated an assessment of the quality of the GC-C-SIRMS measurement for each sample analysed. The same batches of heptadecanoic and methyl heneicosanoate acid were used throughout the entire analyses.

The nominal $\delta^{13} \mathrm{C} \%$ values and standard deviation for the $\mathrm{C}_{17}$ IS and the $\mathrm{C}_{21} \mathrm{GC}$ standard were calculated from replicate preparations of both the sunflower and corn oil IHRMs. These data are summarised cin Table 1. The mean \pm 3 SD was also calculated to give action limits' for the preparation procedure and the GC-CSIRMS measurement.

All of the values obtained for the internal and GC standards remained in-control during the analysis of the authentic single seed vegetable oils. These data show that the derivatisation and extraction procedure and the subsequent stable isotope ratio measurements were consistent in all the samples analysed.

\section{RESULTS AND DISCUSSION}

\section{Authentic $\mathrm{C}_{3}$ single seed vegetable oil samples}

Forty-three authentic single seed vegetable oils were analysed by GC-C-SIRMS. The $\delta^{13} \mathrm{C} \%$ values of the major fatty acids (palmitic, stearic, oleic, linoleic) were determined (as their methyl esters). These data, including the mean and standard deviation, for each oil type investigated are shown in Table 2. Correction of the $\delta^{13} \mathrm{C} \%$ data, for the inclusion of carbon from the derivatising agent, was done using the formula of Goodman \& Brenna (1992). The same batch of methanol was used to derivatise all the samples, and its carbon isotope ratio was determined directly using a Poraplot capillary column in the GC-C-SIRMS system.

The data determined for the $C_{3}$ oils (groundnut, palm, rapeseed, sunflower) disclosed a remarkable homogeneity of fatty acid carbon isotope ratios between the different $\mathrm{C}_{3}$ oil varieties analysed (intervarietal range $-27.6 \%$ to $-32.1 \%$ ). Furthermore, the intravarietal standard deviations (SD range $0 \cdot 2-1.0$ ) of each of the principal fatty acids was found to be only marginally greater than, or of the same order of magnitude as, the standard deviation of the $\mathrm{C}_{17}$ internal standard data (SD 0.5) (Table 1). The latter value indicates experimental variation and hence demonstrates that the natural variation of each of the principal fatty acids within a given variety of oil is relatively small. However, despite the apparent similarity of the $\delta^{13} \mathrm{C} \%$ data, analysis of variance (ANOVA) with EXCEL software demonstrated for each oil type that there was a significant difference between the values obtained for the principal fatty acids. $F$ values ranged from 10.74 for palm oil to 49.52 for sunflower oil, with $\alpha$ approximating to zero in all cases. Discrimination of the isotopes of carbon within the different fatty acids is particularly noteworthy when the chemical similarity and common biochemical precursors of this class of compounds are considered.

$\delta^{13} \mathrm{C} \%$ values are influenced to some extent by growing location, climate and harvest time (O'Leary, 1981). The use of an internal isotopic reference can reduce these effects so that discrimination of the carbon isotopes

Table 1. $C_{17}$ internal standard and $C_{21} G C$ standard: nominal $\delta^{13} \mathrm{C} \%$ values and standard deviation obtained from in-house reference materials

\begin{tabular}{lcr}
\hline $\begin{array}{l}\text { In-house reference } \\
\text { material }\end{array}$ & $\begin{array}{c}\mathrm{C}_{17} \text { internal } \\
\text { standard }\end{array}$ & $\begin{array}{c}\mathrm{C}_{21} \mathrm{GC} \\
\text { standard }\end{array}$ \\
\hline $\begin{array}{l}\text { Sunflower oil } \\
1\end{array}$ & -33.2 & $\mathrm{NA}$ \\
2 & -33.8 & -32.6 \\
3 & -33.2 & -32.0 \\
4 & -34.4 & -32.0 \\
5 & -34.8 & -32.3 \\
& & \\
Corn oil & & -31.4 \\
1 & -34.2 & -31.1 \\
2 & -34.0 & -31.3 \\
3 & -34.0 & -30.9 \\
4 & -34.0 & $\mathrm{NA}$ \\
5 & -34.2 & -31.7 \\
& & 0.6 \\
Mean & -34.0 & -33.6 \\
SD & 0.5 & -29.9 \\
Mean-3 SD & -35.4 & \\
Mean +3 SD & -32.5 & \\
\hline
\end{tabular}

NA, not analysed. 
between the different fatty acids is confined to enzymatic reactions (Faber et al., 1995). In this way, methyl oleate was chosen as an internal reference point for the remaining principal fatty acids to construct fatty acid

Table 2. Authentic single seed vegetable oils: corrected $\delta^{13} \mathrm{C} \%$ values obtained for principal fatty acids

\begin{tabular}{|c|c|c|c|c|}
\hline & $\begin{array}{c}\text { Palmitic } \\
\left(C_{16: 0}\right)\end{array}$ & $\begin{array}{l}\text { Stearic } \\
\left(C_{18: 0}\right)\end{array}$ & $\begin{array}{c}\text { Oleic } \\
\left(C_{18: 1}\right)\end{array}$ & $\begin{array}{c}\text { Linoleic } \\
\left(C_{18: 2}\right)\end{array}$ \\
\hline \multicolumn{5}{|c|}{ Groundnut oil } \\
\hline 123 & $-28 \cdot 7$ & $-29 \cdot 5$ & $-28 \cdot 5$ & -28.4 \\
\hline 124 & -28.8 & $-30 \cdot 2$ & $-28 \cdot 5$ & $-28 \cdot 3$ \\
\hline 93 & $-30 \cdot 0$ & $-32 \cdot 1$ & -28.7 & -28.4 \\
\hline 79 & $-29 \cdot 0$ & -29.6 & $-28 \cdot 0$ & $-28-2$ \\
\hline 84 & $-29 \cdot 1$ & $-31 \cdot 1$ & $-28 \cdot 1$ & $-28 \cdot 5$ \\
\hline 99 & $-29 \cdot 2$ & $-30 \cdot 0$ & $-28 \cdot 0$ & $-28 \cdot 0$ \\
\hline Mean & -29.1 & -30.4 & $-28 \cdot 3$ & $-28 \cdot 3$ \\
\hline SD & 0.5 & $1 \cdot 0$ & 0.3 & $0 \cdot 2$ \\
\hline \multicolumn{5}{|l|}{ Palm oil } \\
\hline 83 & $-31 \cdot 3$ & $-31 \cdot 2$ & -29.8 & $-30 \cdot 1$ \\
\hline 90 & $-30 \cdot 6$ & $-31 \cdot 3$ & -28.9 & $-29 \cdot 6$ \\
\hline 95 & $-30 \cdot 2$ & $-31 \cdot 2$ & -30.6 & $-29 \cdot 8$ \\
\hline 96 & -28.0 & -29.3 & -28.6 & -28.0 \\
\hline 89 & -29.5 & $-30 \cdot 3$ & $-28 \cdot 9$ & -29.5 \\
\hline 105 & $-30 \cdot 2$ & $-31 \cdot 7$ & -30.7 & -30.4 \\
\hline 119 & -30.0 & $-30 \cdot 4$ & $-30 \cdot 3$ & -29.8 \\
\hline 140 & $-30 \cdot 4$ & $-30 \cdot 6$ & $-30 \cdot 5$ & $-30 \cdot 1$ \\
\hline 188 & $-30 \cdot 3$ & $-31 \cdot 6$ & $-29 \cdot 3$ & -29.5 \\
\hline 194 & $-30 \cdot 5$ & -31.6 & -29.8 & -29.7 \\
\hline 210 & -30.7 & $-31 \cdot 1$ & -29.4 & -29.5 \\
\hline 213 & -30.5 & -31.0 & -29.5 & -29.4 \\
\hline 217 & $-30 \cdot 1$ & -30.7 & -28.8 & -28.8 \\
\hline Mean & -30.4 & $-31 \cdot 1$ & $-29 \cdot 5$ & -29.5 \\
\hline $\mathrm{SD}$ & 0.2 & 0.4 & 0.6 & 0.4 \\
\hline \multicolumn{5}{|c|}{ Rapeseed oil } \\
\hline 102 & -30.0 & $-31 \cdot 3$ & -28.4 & -28.9 \\
\hline 120 & -29.0 & $-30 \cdot 2$ & $-28 \cdot 5$ & -29.0 \\
\hline 76 & -29.9 & $-31 \cdot 3$ & -28.6 & $-29 \cdot 3$ \\
\hline 85 & $-29 \cdot 0$ & $-30 \cdot 6$ & $-28 \cdot 1$ & -29.0 \\
\hline 135 & -30.4 & $-32 \cdot 0$ & -30.4 & -29.6 \\
\hline 146 & -30.4 & $-31 \cdot 2$ & $-31 \cdot 1$ & $-30 \cdot 0$ \\
\hline 94 & -29.5 & -29.8 & -28.7 & $-28 \cdot 6$ \\
\hline 100 & -29.5 & -29.3 & -29.2 & -29.0 \\
\hline 173 & -30.4 & $-30 \cdot 2$ & $-28 \cdot 5$ & $-28 \cdot 6$ \\
\hline 207 & $-30 \cdot 1$ & -30.4 & $-28 \cdot 5$ & -28.7 \\
\hline 236 & $-32 \cdot 1$ & -31.0 & $-28 \cdot 5$ & -28.5 \\
\hline Mean & $-30 \cdot 3$ & $-30 \cdot 3$ & $-29 \cdot 1$ & $-28 \cdot 9$ \\
\hline $\mathrm{SD}$ & 0.9 & 0.7 & 1.0 & 0.6 \\
\hline \multicolumn{5}{|c|}{ Sunflower oil } \\
\hline 77 & -30.9 & -29.7 & $-28 \cdot 8$ & $-28 \cdot 3$ \\
\hline 86 & $-32 \cdot 1$ & -31.7 & -29.6 & -28.7 \\
\hline 92 & -30.6 & -31.4 & -29.9 & $-28 \cdot 0$ \\
\hline 97 & $-30 \cdot 0$ & $-30 \cdot 3$ & $-30 \cdot 0$ & $-28 \cdot 0$ \\
\hline 103 & -29.5 & $-30 \cdot 1$ & -29.4 & $-28 \cdot 0$ \\
\hline 122 & $-29 \cdot 3$ & -29.8 & -29.7 & $-27 \cdot 6$ \\
\hline 132 & $-30 \cdot 5$ & $-31 \cdot 2$ & $-30 \cdot 1$ & $-28 \cdot 7$ \\
\hline 145 & $-30 \cdot 1$ & $-31 \cdot 3$ & $-30 \cdot 2$ & -28.9 \\
\hline 157 & -30.4 & $-30 \cdot 8$ & -28.8 & $-28 \cdot 0$ \\
\hline 185 & $-30 \cdot 4$ & $-30 \cdot 3$ & -28.8 & $-28 \cdot 0$ \\
\hline 206 & $-31 \cdot 3$ & $-30 \cdot 3$ & -28.4 & $-27 \cdot 9$ \\
\hline 211 & -31.0 & $-30 \cdot 3$ & -29.4 & $-27 \cdot 8$ \\
\hline 233 & $-30 \cdot 5$ & -30.8 & -29.0 & $-27 \cdot 9$ \\
\hline Mean & -30.6 & -30.7 & $-29 \cdot 1$ & $-28 \cdot 1$ \\
\hline SD & 0.5 & 0.4 & 0.6 & 0.4 \\
\hline
\end{tabular}

isotopic fingerprints for each oil type investigated. These isotopic fingerprints are shown graphically in Figs 1-4. The mean differences of each principal fatty acid relative to oleic acid are plotted and the vertical bars show the

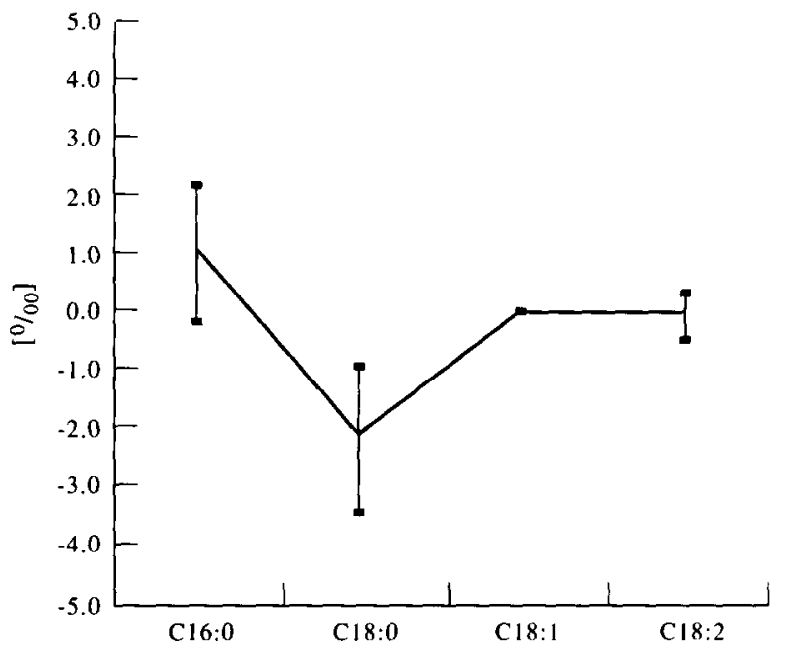

Fig. 1. $\delta^{13} \mathrm{C}$ fingerprint from authentic groundnut oils calculated versus oleic acid $\left(C_{18: 1}\right)$ as internal isotopic reference.

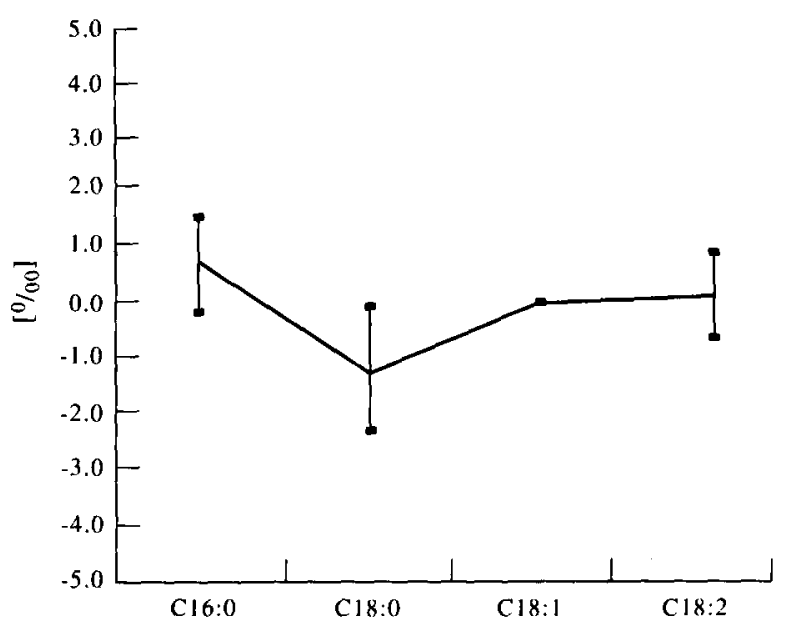

Fig. 2. $\delta^{13} \mathrm{C}$ fingerprint from authentic palm oils calculated versus oleic acid $\left(\mathrm{C}_{18: 1}\right)$ as internal isotopic reference.

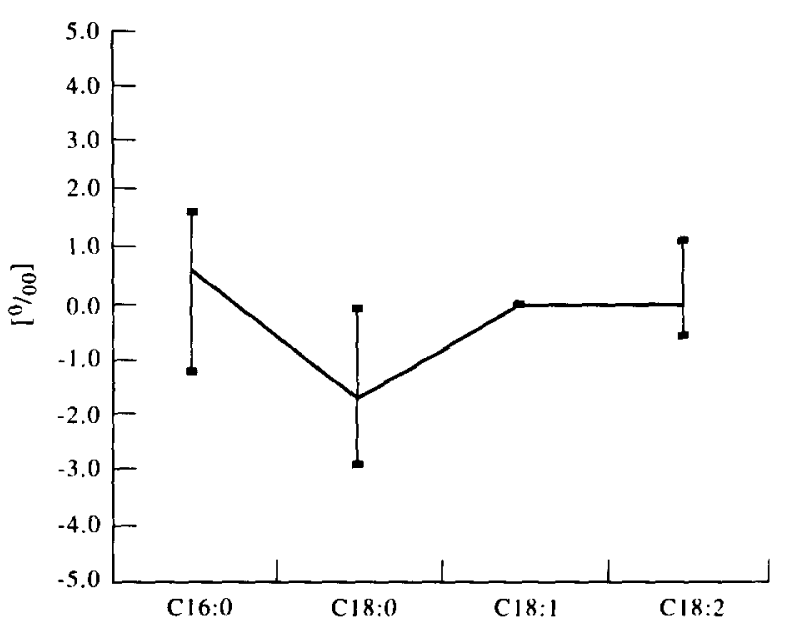

Fig. 3. $\delta^{13} \mathrm{C}$ fingerprint from authentic rapeseed oils calculated versus oleic acid $\left(C_{18: 1}\right)$ as internal isotopic reference. 
range of values obtained for each of the different fatty acids. Palmitic acid was found to be relatively enriched in carbon-13 compared to oleic in groundnut, palm and rapeseed, but not in sunflower oil, where linoleic acid was found to be relatively enriched. Stearic acid was found to be relatively depleted in carbon- 13 compared to oleic acid in all the oils considered.

\section{Canonical discriminant analysis (CDA)}

Visual inspection of the single seed oil data showed no obvious trends for detecting the adulteration of a $\mathrm{C}_{3}$ oil with another $\mathrm{C}_{3}$ variety. In order to assess whether the combined fatty acid $\delta^{13} \mathrm{C} \%$ data could be used to achieve this, it was subjected to canonical discriminant analysis (CDA). This approach was used to find a combination of functions based on fatty acid $\delta^{13} \mathrm{C} \%$ values which maximised the separation between oil types. The data for the principal acids from all 43 authentic oils analysed was submitted to CDA using the statistical software package SPSS; $76 \%$ of the samples were correctly grouped and classified. These observations are illustrated in Fig. 5.

The sunflower oils were separated in the majority of cases from the other varieties on the basis of linoleic acid $813 \mathrm{C} \%$ data. This can be explained by the relatively enriched $\delta 13 \mathrm{C} \%$ values of linoleic acid in the sunflower oils compared to the other $\mathrm{C}_{3}$ oils (Fig. 4).

$\mathrm{CDA}$ indicates that there is a significant correlation between carbon isotope fractionation and plant variety within the classes of oils considered, particularly in the case of sunflower. However, it is clear from Fig. 5 that there is a considerable overlap of oil varieties, and reliable classification would prove difficult using this technique alone. Detection of low levels of adulteration would therefore be impossible. The high degree of overlap is indicative of the overiding discrimination of the Calvin $\left(\mathrm{C}_{3}\right)$ photosynthetic cycle irrespective of plant variety. This observation is supported by the work of

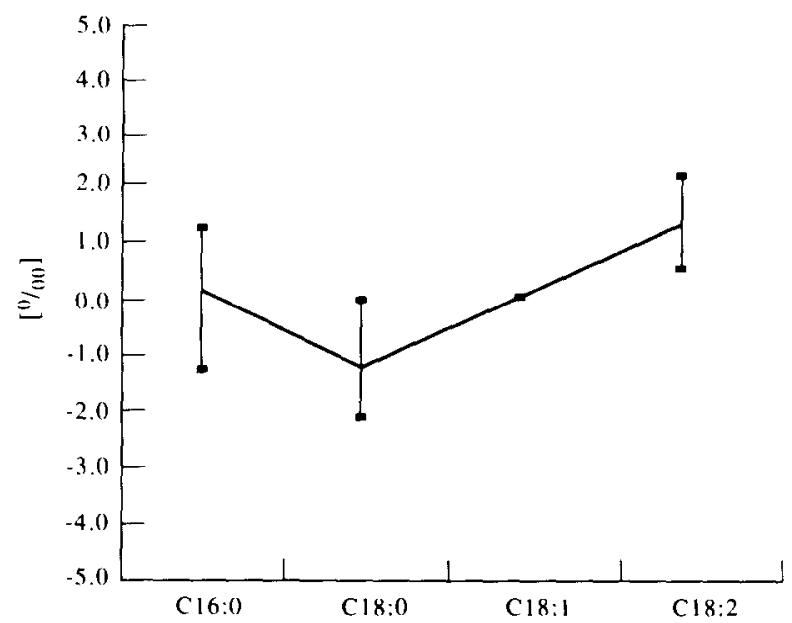

Fig. 4. $\delta^{13} \mathrm{C}$ fingerprint from authentic sunflower oils calculated versus oleic acid $\left(\mathrm{C}_{18: 1}\right)$ as internal isotopic reference.
Bianchi et al. (1993), who found a narrow range of $\delta^{13} \mathrm{C} \%$ values within different oil components from various olive cultivars.

\section{CONCLUSIONS}

IHRMs and internal standard materials were used routinely to monitor the extraction procedure and SIRMS measurement. The quality control data demonstrated that both were performed consistently.

The $\delta^{13} \mathrm{C} \%$ values of the principal fatty acids (palmitic, stearic, oleic and linoleic) were found to fall into the narrow range of $-27.6 \%$ to $-32.1 \%$. However, the mean values of individual FAMEs within the oil varieties considered were found be significantly different using analysis of variance.

Canonical discriminant analysis highlighted the correlation between carbon isotope fractionation and plant variety and the deviation of sunflower oil isotope characteristics from the other oils investigated. This may provide approaches for defining the authenticity of this premium product and further work in this area will be performed.

It is therefore clear that solely determining the fatty acid isotopic fingerprints of $\mathrm{C}_{3}$ oils is insufficient to unambiguously define them, but used in conjunction with other oil analyses it may provide useful information to detect the adulteration of these valuable commodities.

\section{ACKNOWLEDGEMENTS}

The authors would like to thank Dr Colin Moffat of the CSL Food Science Laboratory, Torry, UK, for supplying the authentic vegetable oil samples used in this work.

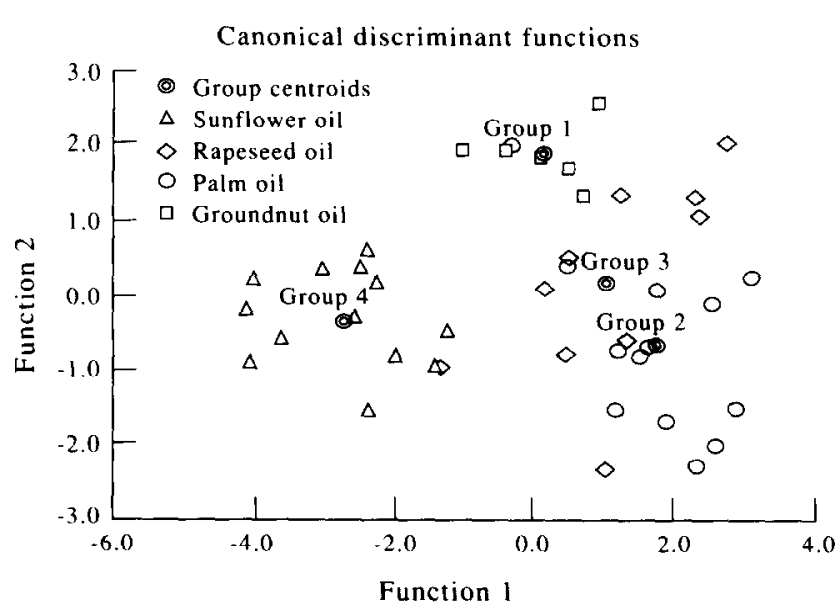

Fig. 5. Canonical discriminant analysis of authentic single seed vegetable oil FAME $\delta^{13} \mathrm{C}$ data. 


\section{REFERENCES}

Bianchi, G., Angerosa, F., Camera, L., Reniero, F. \& Anglani, C. (1993). Stable carbon isotope ratios $\left({ }^{13} \mathrm{C} /{ }^{12} \mathrm{C}\right)$ of olive oil components. J. Agric. Food Chem., 41, 1936-1940.

Bricout, J. \& Koziet, J. (1987). Control of the authenticity of orange juice by isotopic analysis. J. Agric. Food Chem., 35, 758-760.

Brookes, S. T., Barrie, A. \& Davies, J. E. (1991). A rapid ${ }^{13} \mathrm{C} /{ }^{12} \mathrm{C}$ test for determination of corn-syrups in honey. $J$. Assoc. Off. Anal. Chem., 74, 627-629.

Doner, L. W. (1985). Carbon isotope ratios in natural and synthetic citric acid as indicators of lemon juice adulteration. J. Agric. Food Chem., 33, 770-772.

Christie, W. W., ed. (1989). Gas Chromatography of Lipids $-A$ Practical Guide. Oily Press, Ayr, Scotland, Ch. 4.

Doner, L. W. (1991). Verifying the authenticity of plantderived materials by stable isotope ratio and chromatographic methodologies. J. Assoc. Off. Anal. Chem., 74, 14-19.

Faber, B., Krause, B., Dietrich, A. \& Mosandl, A. (1995). Gas-chromatography-isotope ratio mass spectrometry in the analysis of peppermint oil and its importance in authenticity control. J. Essent. Oil Res., 7, 123-131.
FOSFA International (1994). Guideline Specifications, 2nd edn. FOSFA (Federation of Oils, Seeds and Fat Associations) International, London.

Goodman, K. J. \& Brenna, J. T. (1992). High sensitivity tracer detection using high-precision GC-C-SIRMS and highly enriched $\left[\mathrm{U}^{-13} \mathrm{C}\right]$-labelled precursors. Anal. Chem., 64, 1088-1095.

Hamilton, R. J. \& Rossell, J. B., eds (1986). Analysis of Oils and Fats. Elsevier Applied Science, London, Ch. 3, p. 123.

Koziet, J., Rossmann, A., Martin, G. J. \& Ashurst, P. R. (1993). Determination of carbon-13 content of sugars of fruit and vegetable juices. Anal. Chim. Acta, 271, 31-38.

Leatherhead Food Research Association (1994). Authenticity of Vegetable Oils and Fats. Part XX. Determination of Corn Oil Purity by SCIRA. Leatherhead Food Research Association Research Report, May 1994.

O'Leary, M. H. (1981). Carbon isotope fractionation in plants. Phytochemistry, 20, 553-567.

Rossell, J. B. (1991). Purity criteria in edible oils and fats. Fat Sci. Technol., 93, 526-531.

Rossell, J. B. (1994). Stable carbon isotope ratios in establishing maize oil purity. Fat Sci. Technol., 96, 304-308. 